\title{
A 16-week study to compare the effect of vildagliptin versus gliclazide on postprandial lipoprotein concentrations and oxidative stress in patients with type 2 diabetes inadequately controlled with metformin monotherapy
}

\author{
Marcelo R. Nasser Hissa ${ }^{1 *}$, Lilian Loureiro Albuquerque Cavalcante' ${ }^{1}$ Sergio Botelho Guimarães² \\ and Miguel Nasser Hissa ${ }^{3}$
}

\begin{abstract}
Background: Diabetes is closely linked with coronary artery disease, either by means of direct effects of hyperglycemia, or indirectly by its frequent association with dyslipidemia. Any treatment for diabetes that has beyond the capacity of reduce glycated hemoglobin, the propensity to improve lipid profile and reduce weight will bring many benefits to patients.

Method: We compare the effects of vildagliptin with the gliclazide on lipid profile before and after a standardized meal test, on glycemic control and oxidative stress in diabetic patients using metformin without adequate glycemic control. This is a prospective study of 16 weeks with diabetic patients using metformin without adequate glycemic control. Patients were randomized to receive gliclazide 30-120 mg/day or vildagliptin $100 \mathrm{mg} /$ day.
\end{abstract}

Results: 36 patients were randomized, with no loss of follow up. Regarding the lipid profile the difference observed at the end of the study was a higher HDL level in the vildagliptin group compared with gliclazide fasting (62.3 vs. $51.3 \mathrm{mg} / \mathrm{dL}, p=0.021$ ) and postprandial (62.9 vs. $51.1 \mathrm{mg} / \mathrm{dL}, p=0.015)$. We also observed a variation of negative weight (decrease the end compared to the beginning) of the vildagliptin and a positive (increase) in the gliclazide $(-0.3$ vs. $+1.4 \mathrm{Kg}, p=0.048)$. The decrease in A1c was lower in the vildagliptin group compared to gliclazide $(-1.7$ vs. $-2.3 \%, P=0.031$ ), however there was no difference in the number of patients reaching target glycated hemoglobin $<7 \%$ (50 vs. $61.1 \%, p=0.738$ ). Only the group of vildagliptin presented at the end of the study compared to the beginning, decreased insulin values (599.6 vs.705, $59 \mathrm{pg} / \mathrm{ml}, p=0.021$ ), glucagon ( 46.6 vs.65, $2 \mathrm{pg} / \mathrm{ml}, p=0.004$ ) and the marker of oxidative stress TBARS ( $8.0 \mathrm{vs.} 9.0 \mathrm{nmol} \mathrm{MDA} / \mathrm{ml}, p=0.035$ ).

Conclusion: Vildagliptin showed some advantages in addition to metformin in relation to addition of gliclazide. Patients treated with vildagliptin had a higher $\mathrm{HDL}$ at the end of the study, less variance in weight, reduced insulin and glucagon as well as reduction of oxidative stress.

\footnotetext{
*Correspondence: marcelo_hissa@yahoo.com.br

'Department of Surgery, Postgraduate Program, UFC, Fortaleza, Ceara, Brazil

Full list of author information is available at the end of the article
} 


\section{Introduction}

Diabetes is a devastating disease that currently affects more than a billion people worldwide [1, 2]. Patients with diabetes have a significantly increased risk of morbidity and mortality associated with cardiovascular disease and stroke, causing $75 \%$ of all deaths [3-5]. Furthermore, type 2 diabetes mellitus (T2DM) is usually associated with other factors like hypertension, dyslipidemia, obesity and accelerated atherosclerosis risk that contributes to an even higher morbidity and cardiovascular mortality [6].

Free radicals are formed disproportionately in diabetes by glucose oxidation, nonenzymatic glycation of proteins, and the subsequent oxidative degradation of glycated proteins. Abnormally high levels of free radicals and simultaneous decline of antioxidant defense mechanisms can lead to damage of cellular organelles and enzymes, increased lipid peroxidation, and development of insulin resistance. Conversely insulin resistance is associated with atherogenic dyslipidemia, with the postprandial hyperlipidemia playing an important role in this state $[7,8]$. It is well known that impaired clearance from the circulation of intestinally-derived lipoprotein particles and their lipid content contributes to postprandial hyperlipidemia in those with insulin resistance and T2DM [9].

Gliclazide is a second generation sulphonylurea (SU) most prescribed in many countries. It has advantage over others SUs because of its selectivity. Individual SUs express a different selectivity for pancreatic and myocardial SU receptors; gliclazide seems the most selective with respect to pancreatic receptor stimulation, and thus showing a cardiovascular benefits over others SUs [10].

Vildagliptin is a compost of the DPP-4 inhibitor drug class. It is a highly-selective substrate for the DPP-4 catalytic site with a slow reaction rate, which blocks the usually rapid degradation of GLP-1 and glucosedependent insulinotropic peptide (GIP) [11, 12]. Vildagliptin increases plasma level of GLP-1 and GIP, which improves the sensitivity of the $\beta$ - and $\alpha$-cell to glucose; there are also extra-pancreatic effects which contribute to improved insulin sensitivity and attenuate weight gain. In clinical studies, vildagliptin has been shown to reduce $\mathrm{HbA1c}$, fasting plasma glucose (FPG) \& postprandial plasma glucose levels. Furthermore decreased postprandial glycemic excursion might reduce the oxidative stress markers and improve postprandial hyperlipidemia [13].

Results from clinical studies to date indicating that dipeptydyl peptidase-4 (DPP-4) inhibitors reduce total cholesterol are inconsistent. Based on these evidence, this research was designed to evaluate the effect of vildagliptin on the impact of DDP-4 inhibition on lipoprotein metabolism by examining the effects of vildagliptin on postprandial lipid levels and oxidative stress. We hypothesized that in T2DM, treatment with vildagliptin would improve lipoprotein levels and oxidative stress more pronounced than treatment with gliclazide.

\section{Subjects and methods Study design}

This is a 16-week open label randomized prospective study conducted at the Diabetes Research Center/Department of Internal Medicine, Federal University of Ceara, Brazil.

The study protocol was approved by the local Ethical Committee (Comite de etica em pesquisa/ Hospital universitario Walter Cantidio) and all eligible candidates had to provide signed informed consent before enrolling in the study.

\section{Participants}

We enrolled 36 patients with type 2 diabetes who had been inadequately treated with metformin for at least 3 months $\left(\geq 1,000 \mathrm{mg} /\right.$ day) expressed as $\mathrm{HbA}_{1 \mathrm{c}}>7,5 \%$. Eligibility criteria included men or women $18-70$ years of age who were on metformin treatment for $\geq 3$ months on stable dose $(\geq 1000 \mathrm{mg} /$ daily) and body mass index between $\geq 22$ and $\leq 40 \mathrm{~kg} / \mathrm{m} 2$. The exclusion criterias were following: (1) pregnant or nursing women; (2) use of any anti-diabetic treatment within 3 months prior to visit 1 other than metformin; (3) chronic (>7 consecutive days) oral, parenteral or intra-articular corticosteroid treatment within 8 weeks prior to Visit 1; (4) history or evidence of major hepatopathy (aspartate aminotransferase or alanine aminotransferase activities $>2.5$ times the upper limit of normal); (5) ischemic heart disease or cerebrovascular disease; (6) creatinine level $>0.133 \mathrm{mmol} / \mathrm{L}$; (7) major diabetes complications (chronic renal insufficiency, proliferative retinopathy and stroke); (7) extreme dyslipidemia, such as familial hypercholesterolaemia; (8) use of antilipemic drug; (9) and a recent history of alcohol or drug abuse.

\section{Treatment protocol}

The study consisted of a 2-week screening period and a 16-week treatment period with either vildagliptin or gliclazide plus metformin, followed by 4 week on follow up. At the initial interview, height, body weight, vital signs and physical examination were performed. Fasting blood samples were performed to assure the inclusion and exclusion criterias (A1c, fast glucose, hepatic function test, serum blood urea nitrogen and creatinine and hematology). At visit 1 (2 weeks later) selected patients were randomly assigned to either vildagliptin or gliclazide group. Participants assigned to vildagliptin group were instructed to take one capsule $(50 \mathrm{mg})$ before their morning meal and before dinner. Participants assigned 
to gliclazide group were instructed to take the dose of gliclazide before the morning meal. It was allowed to titrate gliclazide to a maximum of $120 \mathrm{mg} /$ daily. Compliance was assessed by pill counting. Blood was also collected at visit 1 (week zero) for the assessment of, A1c, fast glucose, lipid profile (total cholesterol, triglyceride, HDL cholesterol, oxidative stress markers [reactive substances to thiobarbituric acid (TBARS), total antioxidant status (TAOS)]; Insulin, C- peptide, glucagon, GLP-1 and GIP. All laboratory tests were repeated in visit 5 (week 16) (Fig. 1).

\section{Meal test}

Before randomization (week 0) and at week 16 after randomization, a standardized meal test (ensure plus ${ }^{\circ}$ ) was given. It consisted of a milkshake containing $13 \mathrm{~g}$ protein $(16.7 \%), 40 \mathrm{~g}$ carbohydrate $(53.8 \%)$ and $13 \mathrm{~g}$ lipid $(29.5 \%)$ per $300 \mathrm{Kcal}$. The patients thereby fasted overnight and an intravenous catheter was inserted into a forearm vein for blood sampling. Study drug was administered 30 min before consumption of a standardized breakfast meal. The meal was consumed within $5 \mathrm{~min}$, and blood samples were drawn before the meal (fasting state) and $3 \mathrm{~h}$ after the meal (postprandial state) for the assessment of lipid profile.

\section{Assays and methods of dosage}

Plasma glucose was assayed by glucose-oxidase method (Dimension RxL Max Integrated Chemistry System - Siemens AG, Erlangen, Germany); Patients were also instructed to monitor their capillary blood glucose by using a blood glucose monitor (Accu-Chek Performa - Roche Diagnostica Brasil LTDA, São Paulo, SP, Brazil). This was done every 3 to 5 days before each visit (visit 2, 3 and 4), seven times a day (before and $2 \mathrm{~h}$ after breakfast, lunch, dinner, and before supper).

Glycated hemoglobin (A1c) was determined by Highperformance liquid chromatography. Total cholesterol (TC), triglycerides (TG), HDL-cholesterol (HDL), blood urea nitrogen (BUN), creatinine concentrations and hepatic function tests were determined using enzymatic analysis (Hitachi Modular P800 Chemistry Analyzer Roche Diagnostics, Indianapolis, IN, USA). Thiobarbituric Acid Reactive Substances (TBARS) and antioxidant state (TAOS) were measured with the QuantiChromTM Antioxidant Assay Kit (DTAC-100) (BioAssay Systems, Hayward, CA, USA). Insulin, Glucagon, C-Peptide, glucagon like peptide-1 (GLP-1) and gastric inhibitory polypeptide (GIP) were measured with the Human Metabolic Hormone Magnetic Bead Panel 96 Well Plate Assay (EMD Millipore Corp., St. Charles, MO, USA).

\section{Statistical analysis}

In order to characterize the population of each group and compare some characteristics, descriptive analysis of frequency measurements was performed when the variable was qualitative; mean and standard variations when the variable was quantitative. In the comparison of qualitative independent variables the chi-square Pearson test was used. The quantitative variables were tested for normality by the Shapiro-Wilk test. For independent variables, in the presence of normality, the homogeneity of variance of the groups was evaluated using the Levene's test. Given the homogeneity, the difference between groups was tested by applying ANOVA. In case of failure to evidence the homogeneity by Levene's test, the differences between the independent variables were calculated using the Welch test. The distinction between quantitative variables without normality was verified using the Mann-Whitney test. In the case of paired variables that were proved normality, inequalities between groups were analyzed by paired $t$ test. If there was normality, the test used to compare this type of variable was the Wilcoxon. The exact significance was evaluated by two-tailed test.

\section{Results}

The study enrolled 36 patients, 18 randomized to Gliclazide group (mean daily dose $86.8 \pm 28.1 \mathrm{mg}$ ) and 18 for the Vildagliptin. There was no loss of follow up of any of the

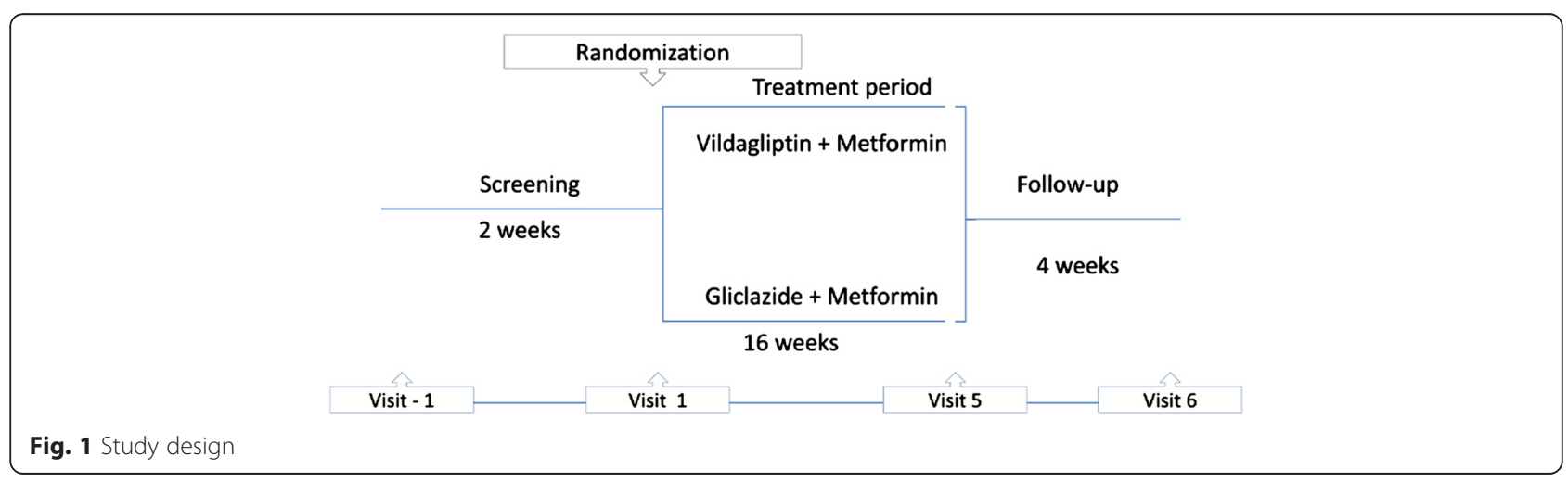


patients. Except for weight, no differences in demographic were observed between the two groups at baseline (Table 1).

There were no differences between the two groups at baseline for biochemical tests. This is also true for lipid profile before and after a standardized meal test concerning total cholesterol, HDL-cholesterol and triglycerides (Table 2).

After the 16 week study, in the stage of post-treatment, total cholesterol and triglyceride levels in fasting and postprandial remained without differences $[(p=0.904$ and $p=0.899)$ and $(p=0.635$ and $p=0.342)$, respectively]. However we observed an increase statistically significant in HDL cholesterol levels in fasting and postprandial ( $p=0.021$ and $p=0.015$, respectively) in the Vildagliptin group (Table 2).

Regarding the weight, there was a difference between the groups before pretreatment. This was higher in the gliclazide compared to vildagliptin group $(82.0 \pm 14.6 \mathrm{~kg}$ and $71.4 \pm 8.0 \mathrm{~kg}$, respectively, $p=0.012)$ and this difference persisted after treatment $(83.4 \pm 14.8$ and $71.0 \pm 8.1 \mathrm{~kg}$, respectively, $p=0.012$ ). It is important to note that while in the gliclazide group, the variation of weight (post-treatment weight less pre-treatment weight) was positive $(1.4 \pm 3.0 \mathrm{~kg})$ in the vildagliptin group it was negative $(-0.3 \pm 2.0 \mathrm{~kg})$, with statistical significance $(p=0.048)$.

No differences were observed between the two groups in fasting and postprandial glucose levels in pretreatment ( $p=0.475$ and $p=0.896$, respectively) as well as post-treatment $(p=0.825$ and $p=0.847)$. A1c also showed no differences between groups in pre and post-treatment $(p=0.109$ and $p=0.800$ respectively) and in the number of patients reaching target glycated hemoglobin $<7 \%$ (50 vs. $61.1 \%$ [ $p=0.738]$, vildagliptin vs. gliclazide respectively).

Patients who used gliclazide showed no significant changes from pre to post-treatment regarding to insulin $(p=0.160)$, glucagon $(p=0.921)$, GLP-1 $(p=0.218)$, GIP $(p=0.201)$ and C-peptide levels $(p=0.193)$. TBAR and TAOS also showed no significant changes ( $p=0.262$ and $p=0.179$, respectively) (Table 3 ).
Regarding the patients who used Vildagliptin, there was a significant decrease in insulin $(p=0.021)$, and glucagon levels $(p=0.004)$. There was significant increase in GLP-1 level $(p=0.026)$. There was a significant decrease in oxidative stress marker TBARS $(p=0.035)$. No difference was observed in TAOS $(p=0.417)$, GIP $(p=0.405)$ and C-peptide levels $(p=0.059)$ (Table 3).

\section{Discussion}

For a long time, the association between cardiovascular disease and metabolic abnormalities during fasting state has been largely studied. However, more recently, metabolic abnormalities in postprandrial state have being recognized as important contributors to cardiovascular disease in T2DM and in other conditions associated with insulin resistance. Postprandial hyperglycemia has been reported as having a greater impact in cardiovascular disease and mortality than fasting hyperglycemia [14]. Others factors, like postprandial hyperlipidemia, have been also addressed as contributors to cardiovascular disease as assessed by several studies [15-21]. Clinical studies in T2DM with DPP-4 inhibitors provide evidences that incretinbased therapies improve fasting and postprandial glycemia and somewhat also dyslipidemia [22-25].

Our results confirm the benefits of vildagliptin, a DPP-4 inhibitor, in the HDL level of diabetic patients. Previous studies initially performed in rats [26] and subsequently in humans, demonstrated an increase in HDL in patients receiving vildagliptin [27]. This effect was observed at a dose of $50 \mathrm{mg} /$ day, but it was greater when using $100 \mathrm{mg} /$ day. This benefit occurs in both treatment-naïve patients, as in those that were already in use of metformin and had vildagliptin added [27-29]. In our study, at baseline there was no difference in HDL between the vildagliptin and gliclazida groups. After 16 weeks of follow up the patients in vildagliptin group showed better HDL in fasting and postprandial than the patients in gliclazide group. However, differently from literature data, we did not observed in our sample any differences in other lipid particles [27, 29].

The evaluation of patients' weight between groups was hampered by a difference already in pre-treatment

Table 1 Patient demographics and baseline characteristics (randomized population)

\begin{tabular}{lll}
\hline Demographic & Gliclazide $(n=18)$ & Vildagliptin $(n=18)$ \\
\hline Age (years) & $55.4 \pm 11.3$ & $59.4 \pm 8.9$ \\
Sex (number of men) & 6 & 12 \\
BMI (kg/m2) & $30.68 \pm 4.3$ & $29.35 \pm 4.3$ \\
Duration of diabetes (years) & $4.4 \pm 2.6$ & $4.3 \pm 2.7$ \\
Duration of previous metformin treatment (months) & All patients were on metformin treatment for $\geq 3$ months on stable dose $(\geq 1000$ mg/daily) \\
Metformin daily dose (mg) & $1457 \pm 373$ & $1584 \pm 528$ \\
Gliclazide daily dose $(\mathrm{mg})$ & $86,80 \pm 28,10$ & - \\
\hline
\end{tabular}


Table 2 Comparision of laboratory tests and weight between the two groups before and after treatment

\begin{tabular}{|c|c|c|c|c|c|c|}
\hline \multirow[b]{3}{*}{ Parametes } & \multicolumn{3}{|l|}{ Pretreatment } & \multicolumn{3}{|c|}{ Post treatment } \\
\hline & \multicolumn{3}{|l|}{ Week 0} & \multicolumn{3}{|l|}{ Week 16} \\
\hline & Gliclazide & Vildagliptin & $P$ & Gliclazide & Vildagliptin & $P$ \\
\hline Fasting TC (mg/dL) & $195.2 \pm 26.9$ & $190.1 \pm 35.8$ & 0.636 & $194.0 \pm 32.2$ & $192.6 \pm 36.4$ & 0.904 \\
\hline Postprandial TC (mg/dL) & $193.1 \pm 25.9$ & $186.8 \pm 34.8$ & 0.544 & $191.3 \pm 32.9$ & $192.8 \pm 37.2$ & 0.899 \\
\hline Fasting HDL (mg/dL) & $51.1 \pm 10.0$ & $60.0 \pm 18.9$ & 0.086 & $51.3 \pm 10.4$ & $62.3 \pm 15.6$ & 0.021 \\
\hline Postprandial HDL (mg/dL) & $50.2 \pm 9.3$ & $59.3 \pm 17.9$ & 0.150 & $51.1 \pm 10.8$ & $62.9 \pm 16.0$ & 0.015 \\
\hline Fasting Triglycerides (mg/dL) & $177.3 \pm 87.3$ & $197.1 \pm 116.0$ & 0.567 & $205.1 \pm 100.3$ & $190.7 \pm 106.2$ & 0.635 \\
\hline Postprandial Triglycerides (mg/dL) & $207.9 \pm 89.3$ & $218,4 \pm 110.0$ & 0.849 & $221.8 \pm 90.1$ & $197.4 \pm 86.1$ & 0.342 \\
\hline Fasting glucose (mg/dL) & $179 \pm 57.9$ & $168.7 \pm 31.3$ & 0.475 & $131.7 \pm 30.5$ & $132.9 \pm 24.8$ & 0.896 \\
\hline Post prandial glucose (mg/dL) & $242.83 \pm 71.7$ & $241.4 \pm 69.5$ & 0.825 & $191.2 \pm 54.8$ & $194.5 \pm 47.4$ & 0.847 \\
\hline A1c (\%) & $9.2 \pm 1.2$ & $8.6 \pm 0.9$ & 0.109 & $6.9 \pm 1.1$ & $6.9 \pm 0.8$ & 0.800 \\
\hline Weight & $82.0 \pm 14.6$ & $71.4 \pm 8.0$ & 0.012 & $83.4 \pm 14.8$ & $71.0 \pm 8.1$ & 0.005 \\
\hline Weight Change (kg) & - & - & - & $+1.4 \pm 3.0$ & $-0.3 \pm 2.0$ & 0.048 \\
\hline
\end{tabular}

Data are means \pm SD. TC total cholesterol, HDL high dense lipoprotein

period, with a higher mean in the gliclazide group. Our data is agreement to the literature [30, 31]. We observed a positive variance (weight gain) in the gliclazide group and a small negative balance (weight loss) in vildagliptin group [32].

Assessing hormonal status of patients within each group before and after treatment, we were able to realize others benefits of vildagliptin. Besides the expected effects in increasing of GLP-1, we also observed significant changes in insulin and glucagon levels in Vildagliptin group.

The main mechanism of action of sulfonylureas through the ATP-sensitive potassium channels leads to increased insulin secretion, therefore were expected higher insulin levels following the introduction of gliclazide. The literature demonstrates that DPP4 inhibitors also lead to increased insulin due to improved beta-cell function, but we observed the opposite effect. Decreased insulin levels may be partially inferred from the reduction of insulin resistance with improved glycemic control [33-35].
The DPP4 inhibition by vildagliptin results in less degradation of GLP-1 leading to the expected effect in improving glycemic control. The decrease in glucagon levels, as observed only in vildagliptin group, is one of the important consequences caused by the increase of GLP-1. Such reduction diminishes the release of glucose mainly in the postprandial period. The intestinal hormone GIP also increased due to the inhibition of DPP4, however, in our sample this increase was insignificant. There was a decrease in TBARS in the group treated with vildagliptin, suggesting an additional benefit in the oxidative stress. This data is in accordance with literature regarding the effects of vildagliptin in oxidative stress [36, 37].

In conclusion, our study of 16 weeks with 36 T2DM showed some advantages in added vildagliptin instead of gliclazide to metformin in the treatment of uncontrolled hyperglycemia. Although both drugs effectively reduce A1c, vildagliptin has additional effects besides glycemic control. Patients treated with vildagliptin had a higher

Table 3 Intragroups comparation of laboratory tests before (week 0) and after treatment (week 16)

\begin{tabular}{|c|c|c|c|c|c|c|}
\hline \multirow[t]{2}{*}{ Parameters } & \multicolumn{3}{|l|}{ Gliclazide } & \multicolumn{3}{|l|}{ Vildagliptin } \\
\hline & Week 0 & Week 16 & $P$ & Week 0 & Week 16 & $P$ \\
\hline Insulin (pg/mL) & $716 \pm 316.7$ & $819.7 \pm 391.9$ & 0.160 & $705.59 \pm 468.8$ & $599.6 \pm 417.7$ & 0.021 \\
\hline Glucagon (pg/mL) & $79.1 \pm 43.1$ & $77.7 \pm 40.0$ & 0.921 & $65.2 \pm 36.1$ & $46.6 \pm 30.8$ & 0.004 \\
\hline A1c (\%) & $9.2 \pm 1.2$ & $6.9 \pm 1.1$ & 0.000 & $8.7 \pm 0.9$ & $6.9 \pm 0.9$ & 0.000 \\
\hline C-peptide (pg/mL) & $1882.0 \pm 690.1$ & $2092.8 \pm 956.2$ & 0.193 & $1627.2 \pm 585.6$ & $1622.6 \pm 609.6$ & 0.059 \\
\hline GLP-1 pg/mL) & $38.3 \pm 25.3$ & $45.5 \pm 21.1$ & 0.218 & $44.7 \pm 38.7$ & $83.8 \pm 74,5$ & 0.026 \\
\hline GIP (pg/mL) & $39.1 \pm 15.2$ & $45.6 \pm 39.0$ & 0.201 & $38.9 \pm 25.7$ & $44.7 \pm 34.8$ & 0.405 \\
\hline TBAR (nmolMDA/mL) & $8.9 \pm 1.4$ & $8.47 \pm 0.9$ & 0.262 & $9.0 \pm 1.6$ & $8.0 \pm 0.7$ & 0.035 \\
\hline TAOS & $215.9 \pm 34.5$ & $264.3 \pm 34.0$ & 0.179 & $257.5 \pm 61.3$ & $205.3 \pm 28.2$ & 0.417 \\
\hline
\end{tabular}


HDL at the end of the study, both fasting and postprandial. TBARS, a marker of oxidative stress, was reduced with vildagliptin treatment, suggesting some ability of this drug in modulating oxidative stress. Finally vildagliptin seems to reduce insulin resistance demonstrated by both reduction in serum levels of insulin and glucagon. To confirm those datas others studies with a longer period of treatment and a greater number of patient are necessary. It is also should be prudent to have studies with others oxidative stress parameters.

\section{Competing interests}

The authors declare that they have no competing interests.

\section{Authors' contributions}

All the authors listed in the manuscript participated in the design of the study and writing of the manuscript. SBG performed the statistical analysis. $\mathrm{MNH}$ conceived of the study and coodination. All the authors read and approved the final manuscript.

\section{Acknowledgment}

This study was financially supported by Novartis. The authors did not receive any reimbursement or financial benefits, and declare that they have no competing interests. Novartis provided vildalgiptin and played no role in the design, methods, data management or analysis, or in the decision to publish.

\section{Author details}

${ }^{1}$ Department of Surgery, Postgraduate Program, UFC, Fortaleza, Ceara, Brazil. ²Department of Surgery, Head, LABCEX, UFC, Fortaleza, Ceara, Brazil. ${ }^{3}$ Department of Medicine, Head of Diabetes and Endocrine-metabolic Unit Research, UFC, Fortaleza, Ceara, Brazil.

Received: 4 February 2015 Accepted: 6 July 2015

Published online: 11 July 2015

\section{References}

1. Wild S, Roglic G, Green A, Sicree R, King H. Global prevalence of diabetes: estimates for the year 2000 and projections for 2030. Diabetes Care. 2004;27(5):1047-53.

2. Cheng YJ, Imperatore G, Geiss LS, Wang J, Saydah SH, Cowie CC, et al. Secular changes in the age-specific prevalence of diabetes among U.S adults: 1988-2010. Diabetes Care. 2013;36:2690-6.

3. Buse JB, Gisnberg HN, Baknis GL, Clark NG, Costa F, Eckel R, et al. Primary prevention of cardiovascular disease in people with diabetes mellitus: a scientific statement from the American Heart Association and the American Diabetes Association. Circulation. 2007;115:114-26.

4. Carnethon MR, Biggs ML, Barzilay J, Kuller LH, Mozaffarian D, Mukamal K, et al. Diabetes and coronary heart disease as a risk factors for mortality in old adults. Am J Med. 2010;123(6):556. e1-9.

5. Preis SR, Hwang SJ, Coady S, Pencina MJ, D'Agostino Sr RB, Savage PJ, et al. Trends in all-cause and cardiovascular disease mortality among women and men with and without diabetes mellitus in the Framinghan Heart study, 1950 to 2005. Circulation. 2009;119:1728-35.

6. Preis SR, Pencina MJ, Hwang SJ, D'Agostino Sr RB, Savage PJ, Levy D, et al. Trends in cardiovascular disease risk factors in individuals with and without diabetes mellitus in the Framinghan Heart study. Circulation. 2009;120:212-20.

7. Brownlee M. Biochemistry and molecular cell biology of diabetic complications. Nature. 2001;414:813-20.

8. Monnier L, Mas E, Ginet C, Michel F, Villon L, Cristol JP, et al. Activation of oxidative stress by acute glucose fluctuations compared with sustained chronic hyperglycemia in patients with type 2 diabetes. JAMA. 2006:295:1681-7.

9. Ginsberg HN, Huang LS. The insulin resistance syndrome: impact on lipoprotein metabolism and atherothrombosis. J Cardiovasc Risk. 2000;7:325-31.
10. Gribble FM, Reimann F. Differential selectivity of insulin secretagogues: mechanisms, clinical implications, and drug interactions. J Diabetes Complications. 2003;17:11-5.

11. Neumiller JJ, Wood L, Campbell RK. Dipeptidyl peptidase-4 inhibitors for the treatment of type 2 diabetes mellitus. Pharmacotherapy. 2010;30:463-84.

12. Mathieu C. The scientific evidence: vildagliptin and the benefits of islet enhancement. Diabetes Obes Metab. 2009;11 Suppl 2:9-17.

13. Rizzo MR, Barbiere MA, Marfella R, Paolisso G. Reduction of oxidative stress and inflammation by blunting daily acute glucose fluctuations in patients with type 2 diabetes. Diabetes Care. 2012;35:2076-82.

14. The DECODE study Group. Glucose tolerance and mortality: comparison of $\mathrm{WHO}$ and American Diabetic Association diagnostic criteria. Lancet. 1999;354:617-21.

15. Stensvold I, Tverdal A, Urdal P, Graff-Iversen S. Non-fasting serum triglyceride concentration and mortality from coronary heart disease and any cause in middle aged Norwegian women. BMJ. 1993;307(6915):1318-22.

16. Tverdal A, Foss OP, Leren P, Holme I, Lund-Larsen PG, Bjartveit K. Serum triglycerides as an independent risk factor for death from coronary heart disease in middle-aged Norwegian men. Am J Epidemiol. 1989;129(3):458-65.

17. Stampfer MJ, Krauss RM, Ma J, Blanche PJ, Holl LG, Sacks FM, et al. A prospective study of triglyceride level, low-density lipoprotein particle diameter, and risk of myocardial infarction. JAMA. 1996;276(11):882-8.

18. Nordestgaard BG, Benn M, Schnohr P, Tybjaerg-Hansen A. Nonfasting triglycerides and risk of myocardial infarction, ischemic heart disease, and death in men and women. JAMA. 2007;298(3):299-308.

19. Freiberg JJ, Tybjaerg-Hansen A, Jensen JS, Nordestgaard BG. Nonfasting triglycerides and risk of ischemic stroke in the general population. JAMA. 2008:300(18):2142-52.

20. Eberly LE, Stamler J, Neaton JD. Relation of triglyceride levels, fasting and nonfasting, to fatal and nonfatal coronary heart disease. Arch Intern Med. 2003;163(9):1077-83.

21. Bansal S, Buring JE, Rifai N, Mora S, Sacks FM, Ridker PM. Fasting compared with nonfasting triglycerides and risk of cardiovascular events in women. JAMA. 2007;298(3):309-16.

22. Matikainen N, Manttari S, Schweizer A, Ulvestad A, Mills D, Dunning $B E$, et al. Vildagliptin therapy reduces postprandial intestinal triglyceride-rich lipoprotein particles in patients with type 2 diabetes. Diabetologia. 2006;49(9):2049-57.

23. DeFronzo RA, Okerson T, Viswanathan P, Guan X, Holcombe JH, MacConell L. Effects of exenatide versus sitagliptin on postprandial glucose, insulin and glucagon secretion, gastric emptying, and caloric intake: a randomized, cross-over study. CurrMed Res Opin. 2008;24(10):2943-52.

24. Hsieh J, Longuet C, Baker C, Qin B, Federico L, Drucker D, et al. The glucagon-like peptide 1 receptor is essential for postprandial lipoprotein synthesis and secretion in hamsters and mice. Diabetologia. 2010;53(3):552-61.

25. Tremblay AJ, Lamarche B, Deacon CF, Weinagel SJ, Couture P. Effect of sitagliptin therapy on postprandial lipoprotein levels in patients with type 2 diabetes. Diabetes Obes Metab. 2011;13:366-71.

26. Apaijai N, Pintana H, Chattipakorn SC, Chattipakorn N. Effects of vildagliptin versus sitagliptin, on cardiac function, heart rate variability and mitochondrial function in obese insulin-resistant rats. Br J Pharmacol. 2013;169(5):1048-57.

27. Rosenstock J, Kim SW, Baron MA, Camisasca RP, Cressier F, Couturier A, et al. Efficacy and tolerability of initial combination therapy with vildagliptin and pioglitazone compared with component monotherapy in patients with type 2 diabetes. Diabetes Obes Metab. 2007;9:175-85.

28. Dejager S, Razac S, Foley JE, Schweizer A. Vildagliptin in drug-naive patients with type 2 diabetes: a 24-week, double-blind, randomized, placebocontrolled, multiple-dose study. Horm Metab Res. 2007;39:218-23.

29. Schweizer A, Couturier A, Foley JE, Dejager S. Comparison between vildagliptin and metformin to sustain reductions in $\mathrm{HbA}(1 \mathrm{c})$ over 1 year in drug-naive patients with Type 2 diabetes. Diabet Med. 2007;24:955-61.

30. Filozof C, Gautier J-F. A comparison of efficacy and safety of vildagliptin and gliclazide in combination with metformin in patients with type 2 diabetes inadequately controlled with metformin alone: a 52-week, randomized study. Diabet Med. 2010;27(3):318-26.

31. Foley JE, Sreenan S. Efficacy and safety comparison between the DPP-4 inhibitor vildagliptin and the sulfonylurea gliclazide after two years of 
monotherapy in drugnaive patients with type 2 diabetes. Horm Metab Res. 2009;41(12):905-9.

32. Ferrannini E, Fonseca V, Zinman B, Matthews D, Ahrén B, Byiers S, et al. Fifty-two-week efficacy and safety of vildagliptin vs. glimepiride in patients with type 2 diabetes mellitus inadequately controlled on metformin monotherapy. Diabetes Obes Metab. 2009;11(2):157-66.

33. Rosenstock J, Foley JE, Rendell M, Landin-Olsson M, Holst JJ, Deacon CF, et al. Effects of the dipeptidyl peptidase-IV inhibitor vildagliptin on incretin hormones, islet function, and postprandial glycemia in subjects with impaired glucose tolerance. Diabetes Care. 2008;31(1):30-5.

34. Mari A, Sallas WM, He YL, Watson C, Ligueros-Saylan M, Dunning BE, et al. Vildagliptin, a dipeptidyl peptidase-IV inhibitor, improves model-assessed beta-cell function in patients with type 2 diabetes. J Clin Endocrinol Metab. 2005;90(8):4888-94

35. Mourad C, Chevalier S, Morais JA, Lamarche M, Gougeon R Antihyperglycaemic medication modifies factors of postprandial satiety in type 2 diabetes. Diabetes Obes Metab. 2009:11(8):819-22.

36. Ávila Dde L, Araújo GR, Silva M, Miranda PH, Diniz MF, Pedrosa ML, et al. Vildagliptin ameliorates oxidative stress and pancreatic beta cell destruction in type 1 diabetic rats. Arch Med Res. 2013;44(3):194-202.

37. Maeda S, Matsui T, Yamagishi S. Vildagliptin inhibits oxidative stress and vascular damage in streptozotocin-induced diabetic rats. Int J Cardiol. 2012;158(1):171-3

\section{Submit your next manuscript to BioMed Central and take full advantage of:}

- Convenient online submission

- Thorough peer review

- No space constraints or color figure charges

- Immediate publication on acceptance

- Inclusion in PubMed, CAS, Scopus and Google Scholar

- Research which is freely available for redistribution 